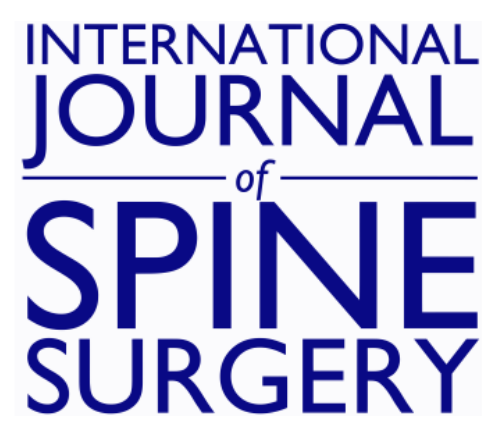

\title{
Improvements in Back and Leg Pain Following a Minimally Invasive Transforaminal Lumbar Interbody Fusion
}

DUSTIN H. MASSEL, BENJAMIN C. MAYO, ANKUR S. NARAIN, FADY Y. HIJJI, PHILIP K. LOUIE, NATHANIEL W. JENKINS, JAMES M. PARRISH and KERN SINGH

Int J Spine Surg 2020, 14 (5) 745-755

doi: https://doi.org/10.14444/7107

http://ijssurgery.com/content/14/5/745

This information is current as of April 26, 2023.

Email Alerts Receive free email-alerts when new articles cite this article. Sign up at: http://ijssurgery.com/alerts 


\title{
Improvements in Back and Leg Pain Following a Minimally Invasive Transforaminal Lumbar Interbody Fusion
}

\author{
DUSTIN H. MASSEL, MD, BENJAMIN C. MAYO, MD, ANKUR S. NARAIN, MD, FADY Y. HIJJI, MD, \\ PHILIP K. LOUIE, MD, NATHANIEL W. JENKINS, MS, JAMES M. PARRISH, MPH, KERN SINGH, MD \\ Department of Orthopaedic Surgery, Rush University Medical Center, Chicago, Illinois
}

\begin{abstract}
Background: Improvement in patient-reported outcomes after minimally invasive transforaminal lumbar interbody fusion (MIS-TLIF) is poorly defined. As such, the purpose of this study was to quantify improvements in Visual Analogue Scale back and leg pain, Oswestry Disability Index (ODI), and Short Form-12 (SF-12) Mental and Physical Composite scores following MIS-TLIF.

Methods: A surgical registry of patients who underwent primary 1-level MIS-TLIF during 2014-2015 was reviewed. Comparisons of Visual Analogue Scale back and leg pain, ODI, and Short Form-12 Mental and Physical Composite scores were performed using paired $t$ tests from preoperative to each postoperative time point. Analysis of variance was used to estimate the degree of improvement in back and leg pain over the first postoperative year. Subgroup analysis was performed for patients presenting with predominant back (pBP) or leg (pLP) pain. Multivariate linear regression was performed to compare patient-reported outcome scores by subgroup.

Results: A total of 106 patients were identified. Visual Analogue Scale back and leg scores, and ODI improved from preoperative scores at all postoperative time points $(P<.05$ for each). Patients with $\mathrm{pBP}(\mathrm{n}=68)$ and patients with pLP $(\mathrm{n}=38)$ reported reductions in both back and leg pain over the first postoperative year $(P<.05$ for each $)$. In the pBP cohort, patients experienced significant reductions in ODI after the first 6 postoperative weeks $(P<.05$ for each). In the pLP cohort, patients experienced significant reductions in ODI throughout the first postoperative year $(P<.05$ for each). Patients with pLP and pBP experienced similar reductions in back pain, whereas patients with pLP experienced significantly greater reductions in leg pain at all postoperative time points $(P<.05$ for each).

Conclusions: The current study suggests patients experience significant improvements in back and leg pain following MIS-TLIF regardless of predominant symptom.

Clinical Relevance: These results can assist surgeons when counseling their patients on the magnitude of symptom improvement they may experience following MIS-TLIF.
\end{abstract}

Minimally Invasive Surgery

Keywords: minimally invasive spine surgery, transforaminal lumbar interbody fusion, patient-reported outcomes, Visual Analogue Scale, back pain, leg pain, Oswestry Disability Index, Short Form-12

\section{INTRODUCTION}

Minimally invasive transforaminal lumbar interbody fusion (MIS-TLIF) is commonly performed to treat low back (LBP) and radicular lower extremity pain. ${ }^{1-4}$ While a majority of patients with LBP will recover from conservative management, approximately $3 \%$ to $4 \%$ of patients with symptomatic spinal stenosis or intervertebral disc herniation will experience refractory symptoms requiring surgical treatment. ${ }^{1-4}$

Symptomatic neural compression presents as radicular leg pain with or without symptomatic LBP. Many surgeons believe MIS-TLIF results in more significant improvement in radicular symptoms compared to LBP. Previous literature supports this claim following lumbar decompression, demonstrating that patients with predominant leg pain (pLP) report greater improvements in leg and back pain, physical function, and patient-reported disability compared to those with predominant back pain (pBP). ${ }^{5,6}$

Patient-reported outcome (PRO) questionnaires are used to evaluate clinical outcomes following surgery. ${ }^{7}$ Prior literature has examined operative characteristics and PROs following lumbar surgery. ${ }^{5,6,8-13}$ However, few studies have assessed the degree of back pain, leg pain, and disability improvement a patient can expect following MISTLIF. Therefore, the purpose of this study is to (1) quantify the improvement in back pain, leg pain, 
patient-reported disability, and mental and physical components of health-related quality-of-life scores over the first postoperative year following MISTLIF and (2) quantify the degree of improvement in these PROs following MIS-TLIF in patients who present with $\mathrm{pBP}$ versus $\mathrm{pLP}$. We hypothesize that MIS-TLIF will result in clinically significant improvements in PROs at 1-year follow-up in both the $\mathrm{pBP}$ and $\mathrm{pLP}$ cohorts.

\section{MATERIALS AND METHODS}

\section{Patient Population}

A prospectively maintained surgical registry of patients who underwent primary, 1-level MIS-TLIF for degenerative spinal pathology was reviewed following institutional review board approval (ORA 14051301). All procedures were performed during 2014 and 2015 by a single surgeon at an academic institution. Patients with a history of lumbar spine surgery, previous spinal trauma, or less than 6 months of postoperative follow-up were excluded from the study.

\section{Demographic and PRO Analysis}

The following demographic, comorbidity, and perioperative variables were used for analysis: age, gender, body mass index (BMI), smoking status, Charlson Comorbidity Index, and preoperative diagnosis. Patients completed the following PRO questionnaires preoperatively and at several postoperative time points ( 6 weeks, 12 weeks, 6 months, and 1 year): Visual Analogue Scale (VAS) for back pain, VAS for leg pain, Oswestry Disability Index (ODI), and the Short Form-12 Health Survey (SF12) Mental Component Summary (MCS) and Physical Component Summary (PCS). The VAS assesses regional pain ranging from 0 (no pain) to 10 (maximum pain). The ODI is a 10-question assessment of patient-reported disability due to their LBP. Questions are scored from 0 to 5, with a maximum score of 50 points (reported as a percentage out of 100); higher scores indicate increasing disability. ${ }^{14}$ The SF-12 is a shortened version of the Short Form36 Health Survey and can be reported in whole, or as separate MCS and PCS scores. ${ }^{15-17}$ Decreasing VAS back, VAS leg, and ODI scores and increasing SF-12 MCS and PCS scores indicate functional improvements. Patients are assigned to complete PRO questionnaires at their homes through an online system 1 week prior to each preoperative, operative, and postoperative visit. If patients do not complete surveys prior to their scheduled appointment time, they are asked to complete them electronically during their office visits before they are seen by the surgeon. Surveys completed in the office are administered by administrative staff via a touch-screen tablet computer.

Primary analysis was initially performed on the entire patient population. Subgroup analysis was then performed in which patients were stratified by the severity of presenting symptoms. Patients with preoperative VAS back pain scores greater than or equal to their VAS leg pain scores were stratified into the $\mathrm{pBP}$ cohort. Patients with preoperative VAS back pain scores less than their VAS leg pain scores were stratified into the pLP cohort.

The percentage of patients achieving a minimum clinically important difference (MCID) for VAS back pain, VAS leg pain, and ODI at any postoperative time point was compared between the $\mathrm{pBP}$ and $\mathrm{pLP}$ cohorts. If a patient's postoperative improvement was greater than the MCID values reported in previous literature, they were determined to have reached the MCID. Values of 1.2, 1.3, and 11.8 were used as the MCID for VAS back pain, ${ }^{18}$ VAS leg pain, ${ }^{18}$ and ODI, ${ }^{18}$ respectively. While numerous other MCID values exist for various spinal diseases, ${ }^{19-22}$ the values selected for these methods were calculated based on degenerative spinal pathologies.

\section{Statistical Methods}

Statistical analysis was performed using Stata/ MP $^{\circledR} 13.1$ for Mac (StataCorp LP, College Station, Texas). Baseline patient characteristics were analyzed using means and standard deviations for continuous variables and percentages for categorical variables. Pairwise comparisons of preoperative to postoperative VAS back pain, VAS leg pain, ODI, and SF-12 MCS and PCS scores were performed using paired $t$ tests for each postoperative time point. Analysis of variance was used to estimate the reduction in back and leg pain that patients reported over the first postoperative year. Subgroup analysis comparing preoperative to postoperative VAS back pain, VAS leg pain, and ODI scores for patients with $\mathrm{pBP}$ or $\mathrm{pLP}$ was also performed using paired $t$ tests for each postoperative time point. Comparisons of preoperative to postoperative pain and disability scores and percentage of patients achieving MCID by $\mathrm{pBP}$ or $\mathrm{pLP}$ subgroups were 
Table 1. Patient population and operative characteristics.

\begin{tabular}{lc}
\hline Parameter & TLIF (N = 106) \\
\hline Age, mean \pm SD, y & $51.2 \pm 12.0$ \\
Sex, \% (n) & $36.8(39)$ \\
$\quad$ Female & $63.2(67)$ \\
$\quad$ Male & \\
BMI, \% (n) & $51.9(55)$ \\
$\quad$ Nonobese (BMI < 30) & $48.1(51)$ \\
$\quad$ Obese (BMI $\geq 30)$ & \\
Smoking status, \% (n) & $83.0(88)$ \\
$\quad$ Nonsmoker & $17.0(18)$ \\
$\quad$ Smoker & $2.6 \pm 2.0$ \\
Comorbidity burden (CCI), mean \pm SD & $6.6 \pm 2.1$ \\
Preoperative VAS back, mean \pm SD & $6.0 \pm 2.5$ \\
Preoperative VAS leg, mean \pm SD & \\
Patients available for follow-up, \% (n) & $100.0(106)$ \\
$\quad$ months & $76.4(81)$ \\
$\quad$ l year & \\
\hline
\end{tabular}

Abbreviations: TLIF, transforaminal lumbar interbody fusion; BMI, body mass index; CCI, Charlson Comorbidity Index; VAS, Visual Analog Scale.

performed using multivariate linear regression adjusting for preoperative characteristics such as age, sex, BMI category, smoking status, and comorbidity burden. Fusion rate was assessed during postoperative clinic visits by either radiograph or computed tomography (CT). A $P$ value of $<.05$ was used to determine statistical significance and all tests were 2-tailed.

\section{RESULTS}

\section{Primary Analysis}

During the time period of 2014 through 2015, a total of 174 patients underwent MIS-TLIF in the surgical registry being used. Following evaluating for inclusion criteria, primary procedures (17 revisions excluded), single-level fusions (7 multilevel fusions excluded), and exclusion criteria, spinal trauma ( 1 excluded due to trauma), failure to follow up at 6 months (43 excluded due to loss to followup), a total of 106 patients who underwent a primary 1-level MIS-TLIF were included in the analysis. All 106 patients reached at least 6 months of postoperative follow-up. Eighty-one of the 106 $(76.4 \%)$ were available for a full year of follow-up. The average patient follow-up was $45.9 \pm 11.0$ weeks. The average patient age was $51.2 \pm 12.0$ years; the majority were male $(63.2 \%)$ and presented with more severe back pain compared to leg pain $(64.2 \%)$. Additional baseline patient characteristics are reported in Table 1.

Table 2 details pairwise comparisons of PRO measures at each postoperative visit. Table 3 details the mean improvement in PRO measures,
Table 2. Pairwise comparison of postoperative to preoperative scores.

\begin{tabular}{|c|c|c|c|}
\hline & Mean $\pm \mathrm{SE}$ & $95 \%$ CI & $P$ value $^{\mathrm{a}}$ \\
\hline \multicolumn{4}{|l|}{ VAS back } \\
\hline Preoperative & $6.6 \pm 0.2$ & $6.2-7.0$ & - \\
\hline 6 weeks & $4.4 \pm 0.2$ & $3.9-4.8$ & $<.001$ \\
\hline 12 weeks & $4.2 \pm 0.3$ & $3.7-4.7$ & $<.001$ \\
\hline 6 months & $3.6 \pm 0.3$ & $3.1-4.1$ & $<.001$ \\
\hline 1 year & $3.7 \pm 0.4$ & $2.8-4.5$ & $<.001$ \\
\hline \multicolumn{4}{|l|}{ VAS leg } \\
\hline Preoperative & $6.0 \pm 0.2$ & $5.6-6.5$ & - \\
\hline 6 weeks & $3.4 \pm 0.3$ & $2.8-4.0$ & $<.001$ \\
\hline 12 weeks & $2.9 \pm 0.3$ & $2.3-3.4$ & $<.001$ \\
\hline 6 months & $2.8 \pm 0.3$ & $2.2-3.3$ & $<.001$ \\
\hline 1 year & $2.7 \pm 0.5$ & $1.6-3.7$ & $<.001$ \\
\hline \multicolumn{4}{|l|}{ ODI } \\
\hline Preoperative & $43.8 \pm 1.6$ & $40.6-46.9$ & - \\
\hline 6 weeks & $39.2 \pm 1.9$ & $35.5-43.0$ & .022 \\
\hline 12 weeks & $31.1 \pm 1.7$ & $27.7-34.5$ & $<.001$ \\
\hline 6 months & $26.2 \pm 2.0$ & $22.2-30.2$ & $<.001$ \\
\hline 1 year & $23.8 \pm 3.2$ & $17.3-30.2$ & $<.001$ \\
\hline \multicolumn{4}{|l|}{$\mathrm{SF}-12 \mathrm{MCS}$} \\
\hline Preoperative & $49.9 \pm 1.4$ & $47.0-52.8$ & - \\
\hline 6 weeks & $51.7 \pm 1.7$ & $48.2-55.1$ & .240 \\
\hline 12 weeks & $53.2 \pm 1.8$ & $49.6-56.7$ & .218 \\
\hline 6 months & $55.5 \pm 1.5$ & $52.5-58.5$ & .001 \\
\hline 1 year & $55.4 \pm 1.7$ & $52.0-58.9$ & .125 \\
\hline \multicolumn{4}{|l|}{ SF-12 PCS } \\
\hline Preoperative & $31.0 \pm 1.4$ & $28.2-33.7$ & - \\
\hline 6 weeks & $30.0 \pm 1.1$ & $27.8-32.2$ & .507 \\
\hline 12 weeks & $35.5 \pm 1.4$ & $32.6-38.3$ & $<.001$ \\
\hline 6 months & $40.7 \pm 1.7$ & $37.2-44.2$ & $<.001$ \\
\hline 1 year & $40.7 \pm 2.1$ & $36.2-45.1$ & $<.001$ \\
\hline
\end{tabular}

Abbreviations: CI, confidence interval; VAS, Visual Analogue Scale; ODI, Oswestry Disability Index; SF-12, Short Form-12; MCS, Mental Component Summary; PCS, Physical Component Summary.

${ }^{\mathrm{a}}$ Boldface indicates statistical significance.

defined as the difference between mean PRO values at final clinical follow-up and mean PRO values at the preoperative evaluation. On average, patients experienced a 2.5 -point $(38.7 \%)$ reduction in back pain and a 3.0 -point $(50.0 \%)$ reduction in leg pain over the first postoperative year $(P<.05$ for each; Table 3). VAS back and VAS leg pain improved from preoperative to each postoperative time point with the greatest amount of improvement in the first 6 postoperative weeks $(P<.05$ for each; Figure 1, Table 2). On average, patients experienced an 11.8-point $(27.2 \%)$ reduction in patient-reported disability (ODI) over the first postoperative year $(P<.05$; Table 3$)$. ODI improved from preoperative to all postoperative time points $(P<.05$; Figure 2, Table 2). On average, patients experienced a 4.0 -point $(8.0 \%)$ increase in SF-12 MCS and a 4.9 point $(16.0 \%)$ increase in SF-12 PCS over the first postoperative year $(P<.05$ for each; Table 3). SF-12 PCS improved from preoperative to all postoperative time points after the 6-week follow-up $(\mathrm{P}<.05$; Figure 2, Table 2). 
Table 3. Mean improvement in PROs over the first postoperative year. ${ }^{a}$

\begin{tabular}{|c|c|c|c|c|c|}
\hline & Preoperative Score, mean $\pm \mathrm{SE}$ & Postoperative Score, mean $\pm \mathrm{SE}$ & Mean Point Improvement & Mean \% Improvement & $P$ value $^{a}$ \\
\hline VAS back pain & $6.6 \pm 0.2$ & $4.0 \pm 0.1$ & 2.5 & 38.7 & $<.001$ \\
\hline VAS leg pain & $6.0 \pm 0.2$ & $3.0 \pm 0.2$ & 3.0 & 50.0 & $<.001$ \\
\hline ODI & $43.3 \pm 1.5$ & $31.6 \pm 1.1$ & 11.8 & 27.2 & $<.001$ \\
\hline SF-12 MCS & $48.9 \pm 1.1$ & $52.9 \pm 0.8$ & 4.0 & 8.0 & $<.001$ \\
\hline SF-12 PCS & $30.7 \pm 1.1$ & $35.6 \pm 0.8$ & 4.9 & 16.0 & $<.001$ \\
\hline
\end{tabular}

Abbreviations: PRO, patient-reported outcome; VAS, Visual Analogue Scale; ODI, Oswestry Disability Index; SF-12, Short Form-12 health survey; MCS, Mental Component Summary; PCS, Physical Component Summary.

${ }^{\mathrm{a} B}$ Boldface indicates statistical significance.

\section{Subgroup Analysis}

\section{Predominant Back Pain versus Predominant Leg Pain}

Patients were stratified with regard to their predominant presenting symptom: 68 patients $(64.2 \%)$ had pBP and 38 patients $(35.8 \%)$ had pLP. Table 4 details baseline patient demographics and characteristics of these groups. On average, patients with pBP were more likely to be male $(70.6 \%$ versus $50.0 \%, P=.035)$ and had higher preoperative VAS back scores $(7.29$ versus 5.27, $P<.001)$. There were no differences between groups in age, BMI, smoking status, comorbidity burden, preoperative diagnosis, or fusion rate $(P>.05$ for each).

Table 5 details the pairwise comparisons of preoperative to postoperative $\mathrm{PRO}$ measures for each cohort. Table 6 details the comparisons of the changes from preoperative to postoperative pain and disability scores between cohorts. On average, patients with pBP experienced a 2.8-point (38.1\%) and a 2.1-point $(38.8 \%)$ reduction in back pain and

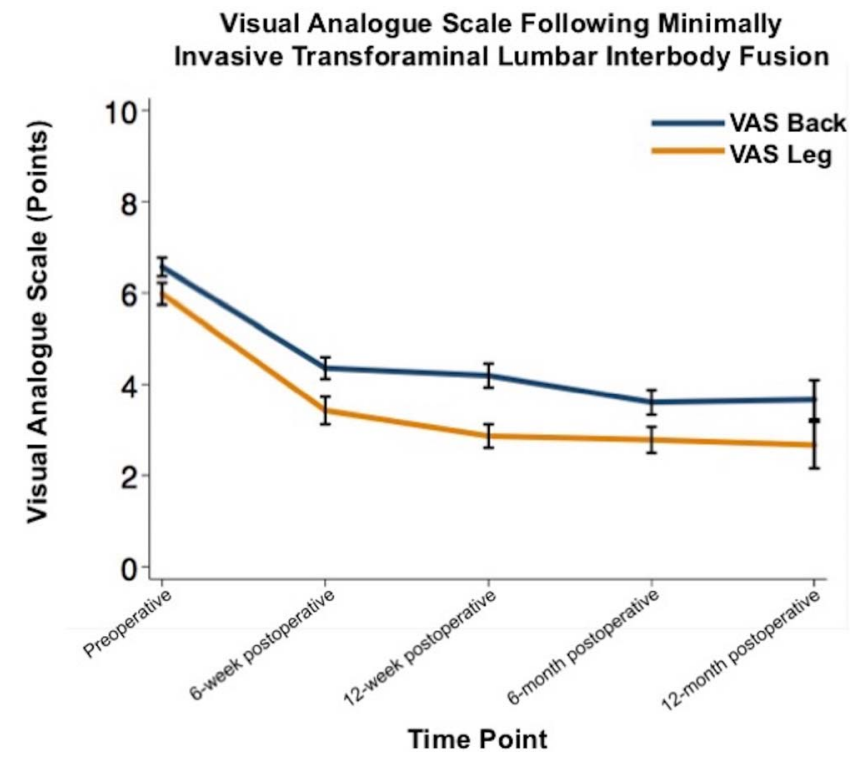

Figure 1. Improvements in Visual Analogue Scale (VAS) back and leg pain from preoperative to postoperative visits following minimally invasive transforaminal lumbar interbody fusion. leg pain, respectively, over the first postoperative year $(P<.05$ for each; Table 7$)$. Patients with $\mathrm{pBP}$ experienced reductions in both back and leg pain from preoperative to all postoperative time points $(P<.05$ for each; Figure 3, Table 5). On average, patients with pLP experienced a 2.2-point $(40.6 \%)$ and a 4.6 -point $(64.8 \%)$ reduction in back and leg pain, respectively, over the first postoperative year $(P<.05$ for each; Table 7$)$. Patients with pLP experienced reductions in both back and leg pain from preoperative to all postoperative time points $(P<.05$ for each; Figure 3, Table 5). Patients with pLP and $\mathrm{pBP}$ experienced similar reductions in back pain over the first postoperative year, whereas patients with pLP experienced significantly greater reductions in leg pain at all postoperative time points $(P<.05$ for each; Table 6$)$. Patients with $\mathrm{pBP}$ experienced a 9.7-point $(22.4 \%)$ reduction in ODI over the first postoperative year, while patients with

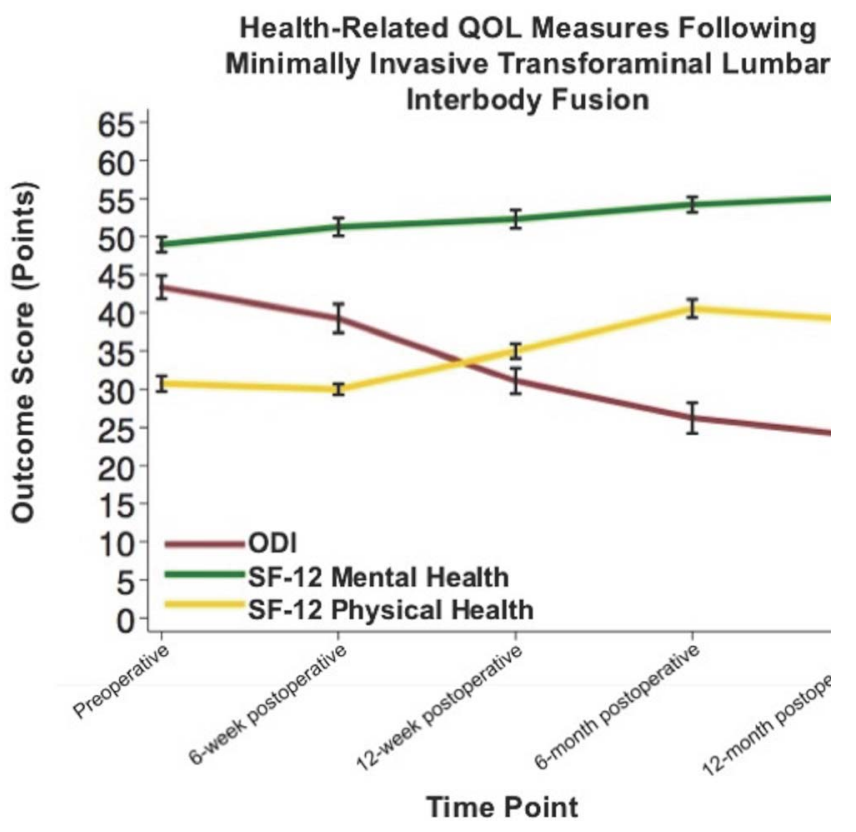

Figure 2. Improvements in Oswestry Disability Index (ODI), Short Form-12 (SF-12) Mental Component Summary (MCS) and Physical Component Summary (PCS) scores from preoperative to postoperative visits following minimally invasive transforaminal lumbar interbody fusion. 
Table 4. Baseline and postoperative characteristics stratified by primary back and primary leg pain groups.

\begin{tabular}{|c|c|c|c|}
\hline & $\mathrm{pBP}(\mathrm{n}=68)$ & pLP $(n=38)$ & $P$ value $^{\mathrm{a}, \mathrm{b}}$ \\
\hline Age, mean $\pm \mathrm{SD}, \mathrm{y}$ & $50.10 \pm 11.61$ & $53.26 \pm 12.47$ & .193 \\
\hline Sex, \% (n) & & & .035 \\
\hline Male & $70.5(48)$ & $50.0(19)$ & \\
\hline Female & $29.5(20)$ & $50.0(19)$ & \\
\hline BMI, \% (n) & & & 909 \\
\hline Nonobese $(\mathrm{BMI}<30)$ & $51.4(35)$ & $52.6(20)$ & \\
\hline Obese (BMI $\geq 30$ ) & $48.5(33)$ & $47.3(18)$ & \\
\hline Smoking status, \% (n) & & & .807 \\
\hline Nonsmoker & $82.35(56)$ & $84.21(32)$ & \\
\hline Smoker & $17.65(12)$ & $15.79(6)$ & \\
\hline $\begin{array}{l}\text { Comorbidity burden }(\mathrm{CCI}) \\
\text { mean } \pm \mathrm{SD}\end{array}$ & $2.51 \pm 2.02$ & $2.83 \pm 1.93$ & .439 \\
\hline $\begin{array}{l}\text { Preoperative VAS back, } \\
\text { mean } \pm \mathrm{SD}\end{array}$ & $7.29 \pm 1.83$ & $5.27 \pm 2.00$ & $<.001$ \\
\hline $\begin{array}{c}\text { Preoperative VAS leg, } \\
\text { mean } \pm \mathrm{SD}\end{array}$ & $5.34 \pm 2.71$ & $7.13 \pm 1.55$ & $<.001$ \\
\hline \multicolumn{4}{|l|}{ Preoperative diagnosis, \% (n) } \\
\hline Spondylolisthesis & $30.8(21)$ & $26.3(10)$ & .620 \\
\hline Recurrent herniated disc & $38.2(26)$ & $36.8(14)$ & .673 \\
\hline Degenerative disc disease & $19.1(13)$ & $26.3(10)$ & .389 \\
\hline Central stenosis & $55.8(38)$ & $55.2(21)$ & .951 \\
\hline Foraminal stenosis & $2.9(2)$ & $10.5(4)$ & .105 \\
\hline \multicolumn{4}{|l|}{ Postoperative, \% (n) } \\
\hline Fusion rate & $97.0(65)$ & $97.3(36)$ & .934 \\
\hline
\end{tabular}

Abbreviations: pBP, predominant back pain; $\mathrm{pLP}$, predominant leg pain; BMI, body mass index; CCI, Charlson Comorbidity Index; VAS, Visual Analogue Scale.

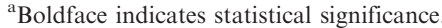

${ }^{\mathrm{b}} P$ value calculated using $\chi^{2}$ analysis (categorical) or Student $t$ test (continuous).

pLP experienced a 15.4-point $(35.4 \%)$ reduction $(P$ $<.05$ for each; Table 7). Patients with pBP experienced reductions in ODI after the 6-week postoperative visit and over the full postoperative year for patients in the pLP cohort $(P<.05$ for each; Figure 3, Table 5). Patients with pLP experienced significantly greater reductions in ODI
Table 6. Comparison of change from preoperative to postoperative pain and disability scores by predominant back or leg pain.

\begin{tabular}{lccc}
\hline & $\begin{array}{c}\text { pBP }(\mathbf{n}=\mathbf{6 8}), \\
\text { mean } \pm \mathbf{S E}\end{array}$ & $\begin{array}{c}\mathbf{p L P}(\mathbf{n}=\mathbf{3 8}), \\
\text { mean } \pm \mathbf{S E}\end{array}$ & $\boldsymbol{P}$ value \\
& & & \\
Change in VAS back & & & \\
$\Delta$ VAS back at 6 weeks & $-2.6 \pm 0.3$ & $-1.7 \pm 0.4$ & .142 \\
$\Delta$ VAS back at 12 weeks & $-2.5 \pm 0.4$ & $-2.1 \pm 0.5$ & .852 \\
$\Delta$ VAS back at 6 months & $-3.3 \pm 0.4$ & $-2.2 \pm 0.6$ & .114 \\
$\Delta$ VAS back at 1 year & $-3.0 \pm 0.6$ & $-2.4 \pm 0.7$ & .333 \\
Change in VAS leg & & & \\
$\Delta$ VAS leg at 6 weeks & $-1.8 \pm 0.4$ & $-4.0 \pm 0.5$ & $\mathbf{. 0 0 7}$ \\
$\Delta$ VAS leg at 12 weeks & $-2.1 \pm 0.4$ & $-4.9 \pm 0.4$ & $<.001$ \\
$\Delta$ VAS leg at 6 months & $-2.1 \pm 0.4$ & $-5.1 \pm 0.5$ & $<.001$ \\
$\Delta$ VAS leg at 1 year & $-2.5 \pm 0.5$ & $-4.8 \pm 0.9$ & $\mathbf{. 0 2 8}$ \\
Change in ODI & & & \\
$\Delta$ ODI at 6 weeks & $-1.4 \pm 2.6$ & $-9.9 \pm 2.7$ & $\mathbf{. 0 2 5}$ \\
$\Delta$ ODI at 12 weeks & $-11.1 \pm 2.4$ & $-14.5 \pm 2.5$ & .346 \\
$\Delta$ ODI at 6 months & $-16.1 \pm 2.4$ & $-20.3 \pm 3.1$ & .206 \\
$\Delta$ ODI at 1 year & $-19.0 \pm 4.6$ & $-20.6 \pm 5.5$ & .889 \\
\hline
\end{tabular}

Abbreviations: VAS, Visual Analogue Scale; ODI, Oswestry Disability Index; pBP, predominant back pain; pLP, predominant leg pain.

${ }^{a}$ Boldface indicates statistical significance.

${ }^{\mathrm{b}} P$ values calculated using multivariate linear regression adjusted for age, sex, BMI category, smoking status, and comorbidity burden.

${ }^{\mathrm{c}}$ Change in VAS or ODI = postoperative score ( 6 weeks, 12 weeks, 6 months, 1 year) - preoperative score

at the 6-week follow-up visit compared to the pBP cohort $(P<.05$; Table 6$)$.

\section{Minimum Clinically Important Difference}

Information on the achievement of MCID for each of the PROs is provided in Table 8 . There were no differences in the percent of patients achieving MCID for VAS back (pBP: $80.9 \%$ versus pLP: $76.3 \% ; P=.574$ ), VAS leg (pBP: $82.4 \%$ versus $\mathrm{pLP}$ : $92.1 \% ; P=.235$ ), or ODI (pBP: $61.8 \%$ versus $\mathrm{pLP}$ :

Table 5. Pairwise comparison of postoperative to preoperative pain and disability scores by predominant back or leg pain

\begin{tabular}{|c|c|c|c|c|c|c|}
\hline & \multicolumn{3}{|c|}{ Predominant back pain $(n=68)$} & \multicolumn{3}{|c|}{ Predominant leg pain $(n=38)$} \\
\hline & Mean $\pm \mathrm{SE}$ & $95 \% \mathrm{CI}$ & $P$ value & Mean $\pm \mathrm{SE}$ & $95 \%$ CI & $P$ value $^{\text {a }}$ \\
\hline \multicolumn{7}{|l|}{ VAS back } \\
\hline Preoperative & $7.4 \pm 0.2$ & $7.0-7.9$ & - & $5.3 \pm 0.3$ & $4.6-6.0$ & - \\
\hline 6 weeks & $4.8 \pm 0.3$ & $4.3-5.4$ & $<.001$ & $3.6 \pm 0.4$ & $2.7-4.4$ & $<.001$ \\
\hline 12 weeks & $4.8 \pm 0.3$ & $4.1-5.4$ & $<.001$ & $3.2 \pm 0.4$ & $2.4-4.0$ & $<.001$ \\
\hline 6 months & $3.9 \pm 0.3$ & $3.2-4.5$ & $<.001$ & $3.1 \pm 0.4$ & $2.2-4.0$ & $<.001$ \\
\hline 1 year & $4.6 \pm 0.4$ & $3.7-5.5$ & $<.001$ & $2.4 \pm 0.7$ & $0.9-4.0$ & .006 \\
\hline \multicolumn{7}{|l|}{ VAS leg } \\
\hline Preoperative & $5.4 \pm 0.3$ & $4.8-6.1$ & - & $7.1 \pm 0.3$ & $6.6-7.6$ & - \\
\hline 6 weeks & $3.6 \pm 0.4$ & $2.8-4.4$ & $<.001$ & $3.1 \pm 0.5$ & $2.2-4.0$ & $<.001$ \\
\hline 12 weeks & $3.2 \pm 0.4$ & $2.5-3.9$ & $<.001$ & $2.3 \pm 0.3$ & $1.6-2.9$ & $<.001$ \\
\hline 6 months & $3.1 \pm 0.4$ & $2.3-3.8$ & $<.001$ & $2.2 \pm 0.4$ & $1.4-3.0$ & $<.001$ \\
\hline 1 year & $2.9 \pm 0.7$ & $1.5-4.4$ & $<.001$ & $2.3 \pm 0.8$ & $0.5-4.1$ & $<.001$ \\
\hline \multicolumn{7}{|l|}{ ODI } \\
\hline Preoperative & $43.7 \pm 2.0$ & $39.7-47.7$ & - & $43.9 \pm 2.7$ & $38.5-49.3$ & - \\
\hline 6 weeks & $42.3 \pm 2.3$ & $37.8-46.9$ & .594 & $33.9 \pm 3.1$ & $27.7-40.2$ & $<.001$ \\
\hline 12 weeks & $32.3 \pm 2.3$ & $27.7-36.9$ & $<.001$ & $29.0 \pm 2.4$ & $24.2-33.9$ & $<.001$ \\
\hline 6 months & $27.4 \pm 2.6$ & $22.2-32.5$ & $<.001$ & $24.1 \pm 3.1$ & $17.6-30.5$ & $<.001$ \\
\hline 1 year & $27.7 \pm 3.7$ & $19.9-35.5$ & $<.001$ & $18.7 \pm 5.3$ & $7.2-30.1$ & .003 \\
\hline
\end{tabular}

Abbreviations: CI, confidence interval; VAS, Visual Analogue Scale; ODI, Oswestry Disability Index.

${ }^{a}$ Boldface indicates statistical significance. 
Table 7. Improvement in PROs over the first postoperative year by predominant back pain or leg pain.

\begin{tabular}{|c|c|c|c|c|c|}
\hline & Preoperative score, mean $\pm \mathrm{SE}$ & Postoperative score, mean $\pm \mathrm{SE}$ & Mean point improvement & Mean \% improvement & $P$ value $^{\mathrm{a}}$ \\
\hline \multicolumn{6}{|c|}{ Predominant back pain } \\
\hline VAS back pain & $7.3 \pm 0.2$ & $4.5 \pm 0.2$ & 2.8 & 38.1 & $<.001$ \\
\hline VAS leg pain & $5.3 \pm 0.3$ & $3.3 \pm 0.2$ & 2.1 & 38.8 & $<.001$ \\
\hline ODI & $43.3 \pm 1.9$ & $33.6 \pm 1.4$ & 9.7 & 22.4 & $<.001$ \\
\hline \multicolumn{6}{|c|}{ Predominant leg pain } \\
\hline VAS back pain & $5.3 \pm 0.3$ & $3.2 \pm 0.2$ & 2.2 & 40.6 & $<.001$ \\
\hline VAS leg pain & $7.1 \pm 0.3$ & $2.5 \pm 0.2$ & 4.6 & 64.8 & $<.001$ \\
\hline ODI & $43.4 \pm 2.6$ & $28.0 \pm 1.6$ & 15.4 & 35.4 & $<.001$ \\
\hline
\end{tabular}

Abbreviations: PRO, patient-reported outcome; VAS, Visual Analogue Scale; ODI, Oswestry Disability Index; SF-12, Short Form-12 health survey; MCS, Mental Component Summary; PCS, Physical Component Summary.

${ }^{a}$ Boldface indicates statistical significance.

$68.4 \% ; P=.459)$ between patients who presented with $\mathrm{pBP}$ versus $\mathrm{pLP}$.

\section{DISCUSSION}

MIS-TLIF is frequently performed to reduce symptoms resulting from neural compression and to alleviate clinically significant LBP. Although PROs are commonly used to evaluate functional improvements following spine surgery, few studies have quantified the degree of improvement patients can expect following lumbar fusion surgery. ${ }^{19,23,24}$ Therefore, the purpose of this study was to quantify the change in PROs a patient can expect over the first postoperative year, and determine the degree of improvement of PROs in patients who present with $p B P$ versus $p L P$ following MIS-TLIF.

The results of the current study suggest that patients will experience significant improvements in both back pain and leg pain following MIS-TLIF.

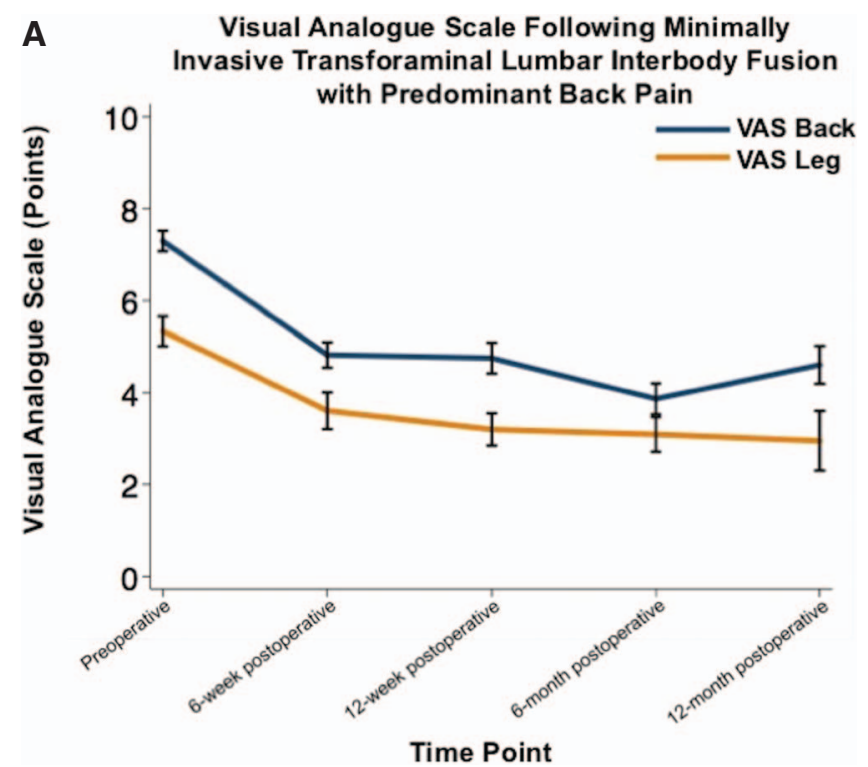

Patients generally report the majority of their pain improvement within the first 6 postoperative weeks. This is intuitive as symptom improvement following surgical decompression of an affected nerve root is often apparent in the initial postoperative period. ${ }^{12,13,25-27}$ Over the first postoperative year, a patient can expect a $38.7 \%$ reduction in their back pain and a $50.0 \%$ reduction in their leg pain. The leg pain improvement is likely resulting from a combination of direct decompression via the MIS approach and indirect decompression via the restoration of disc space height by placement of the interbody cage. In contrast, LBP improvement likely results from fusion of the affected segment. In addition to the low back and leg pain improvements, patients report improvements in disability and physical-component quality-of-life scores, and can expect a $27.2 \%$ reduction in disability and a $16.0 \%$ increase in physical-component quality of

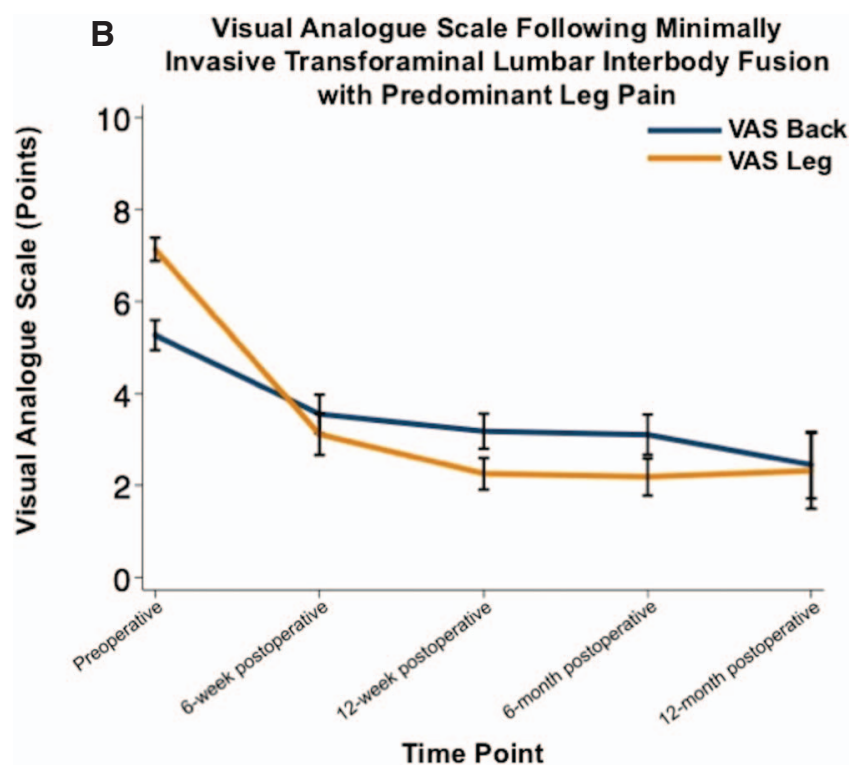

Figure 3. (A) Improvements in Visual Analogue Scale (VAS) back and leg pain from preoperative to postoperative visits following minimally invasive transforaminal lumbar interbody fusion in patients with predominant back pain. (B) Improvements in VAS back and leg pain from preoperative to postoperative visits following minimally invasive transforaminal lumbar interbody fusion in patients with predominant leg pain. 
Table 8. Percentage of patients who achieved a minimum clinically important difference by subgroup.

\begin{tabular}{lccc}
\hline & pBP $(\mathbf{n}=\mathbf{6 8}), \boldsymbol{\%}(\mathbf{n})$ & $\mathbf{p L P}(\mathbf{n}=\mathbf{3 8}), \boldsymbol{\%}(\mathbf{n})$ & $\boldsymbol{P}$ value $^{\mathbf{a}}$ \\
\hline VAS back pain & $80.9(55)$ & $76.3(29)$ & .574 \\
VAS leg pain & $82.4(56)$ & $92.1(35)$ & .235 \\
ODI & $61.8(42)$ & $68.4(26)$ & .459 \\
\hline
\end{tabular}

Abbreviations: VAS, Visual Analog Scale; ODI, Oswestry Disability Index; pBP, predominant back pain; pLP, predominant leg pain.

${ }^{\mathrm{a}} P$ values calculated using multivariate linear regression adjusted for age, sex, body mass indes category, smoking status, and comorbidity burden.

life. This information can be applied to counseling patient expectations regarding their return to activities and level of performance once they return.

The current study also examined the degree of symptom improvement following MIS-TLIF among patients who present with $\mathrm{pBP}$ or $\mathrm{pLP}$. The results demonstrate that patients experience the greatest improvement in their respective predominant symptom: patients with $\mathrm{pBP}$ report greater reductions in back pain than leg pain, while patients with pLP report greater reductions in leg pain than back pain. This is expected, as the predominant symptom has a higher preoperative pain score and thus has the greatest potential for improvement. Furthermore, patients with pLP report greater improvements in leg pain than patients with $\mathrm{pBP}$ experience in back pain. This is likely attributable to the distinct presence of neural compression which is addressed via direct decompression and indirect decompression via interbody device placement. In contrast, the etiology of LBP is multifactorial and not all components may be addressed by the surgery.

In general, patients presenting with $\mathrm{pBP}$ can expect a $38.1 \%$ reduction in their back pain, a $38.8 \%$ reduction in their leg pain, and a $22.4 \%$ reduction in patient-reported disability over the first postoperative year. Similarly, patients with pLP can expect a $40.6 \%$ reduction in their back pain, a $64.8 \%$ reduction in their leg pain, and a $35.4 \%$ reduction in patient-reported disability over the first postoperative year. These results suggest that regardless of presenting symptoms, a majority of patients undergoing MIS-TLIF will report significant improvements in patient-reported disability and pain symptoms. Interestingly, patients presenting with pLP report more significant reductions in their predominant presenting symptom than those in the $\mathrm{pBP}$ cohort and report greater reductions in patient-reported disability. This finding suggests that leg pain may contribute more towards a patient's perceived disability than LBP. Anecdotally, leg pain may hinder ambulation, and thus disrupt several normal daily activities. In contrast, back pain may cause discomfort but may be less likely to interfere with these activities. Similarly, it is perhaps easier to modify bodily movements in order to perform daily activities with back pain compared to leg pain. Thus, leg pain contributes to a greater perceived disability.

The association between leg pain and patientreported disability is further illustrated by the achievement of MCID between $\mathrm{pBP}$ and $\mathrm{pLP}$ cohorts. The majority of patients with $\mathrm{pBP}$ or $\mathrm{pLP}$ achieved MCID in LBP, leg pain, and patientreported disability. However, patients presenting with pLP are more likely to reach MCID for their leg pain and patient-reported disability compared to patients presenting with $\mathrm{pBP}$. Patients presenting with $\mathrm{pBP}$ may be more likely to reach MCID for their back pain than patients presenting with pLP, although these differences did not reach statistical significance. While patients presenting with either $\mathrm{pBP}$ or pLP can expect to achieve MCID in both back and leg pain, patients presenting with pLP will experience a larger improvement in their degree of leg pain, whereas both cohorts will experience similar improvements in their degree of back pain. When counseling patients on postoperative outcomes, practitioners should convey accurate expectations for the degree of improvement patients should experience after MIS-TLIF. The evidence suggests that patients can expect significant improvements in back pain, leg pain, and patientreported disability after MIS-TLIF regardless of presenting symptoms.

As the pLP cohort contained a greater percentage of female patients, demographic differences must be taken into consideration. Multiple previous studies have analyzed the association between PRO measures and gender. ${ }^{28-33}$ In a study of 98 patients undergoing lumbar herniation surgery, Häkkinen et $\mathrm{al}^{30}$ reported that females had higher preoperative ODI and VAS back scores, with similar VAS leg scores compared to males. However, no significant gender differences were seen in VAS back, VAS leg, and ODI at any postoperative time point. Additionally, in a prospective multicenter evaluation of 214 patients, Gautschi et $\mathrm{al}^{29}$ demonstrated that females had higher VAS back, VAS leg, and ODI scores preoperatively. Sex-related differences were not present postoperatively, as there were no differences in mean improvement in VAS back, VAS leg, and ODI scores at 6-week, 6-month, and 
1-year follow-up. As such, gender does not explain the patterns of improvement in PROs in our study both for the entire study population and for the individual $\mathrm{pLP}$ and $\mathrm{pBP}$ cohorts.

Parker et $\mathrm{al}^{34}$ evaluated the predictive power of 3month patient reported outcomes on 12-month outcomes following lumbar spine surgery. When assessing 3-month EQ-5D and ODI scores, they observed a statistically significant correlation with 12-month scores when looking at the cohort as a whole although, at the individual level, patients who had not demonstrated short-term improvement were nonetheless observed to improve by 12 months. Conversely, patients who had demonstrated short-term improvement were able to achieve an improvement by 12 months. While 3-month outcomes may be predictive, this latter finding underscores the importance of long-term follow-up $(\geq 12$ months). Patient improvement and pseudoarthrosis can still be a valid concern from at evaluations of up to 1 year and beyond.

The results of the current study are similar to the results presented in prior literature. Gum et al. ${ }^{35}$ compared health-related quality of life outcome measures among patients who underwent lumbar fusion surgery and reported the majority of patients experienced significant symptom improvement following surgery, as measured by the numerical rating scale (NRS) back pain, NRS leg pain, ODI, and Short Form-36. Of note, the NRS is a numerical scale in which a patient reports their pain level from 0 to 10 , comparable to the VAS used in the current study. The majority of patients that experienced improvements following surgery reported a mean change of 4.2, 3.9, and 22.4 points for NRS back, NRS leg, and ODI, respectively. Although not reported directly, the patient population experienced a $42.9 \%$ improvement in back pain, $41.3 \%$ improvement in leg pain, and $32.8 \%$ improvement in ODI. ${ }^{35}$ Similarly, others ${ }^{24,36}$ analyzed PROs among obese and morbidly obese patients and among grade I degenerative spondylolisthesis patients following MIS-TLIF, respectively. Although not explicitly reported, among obese and morbidly obese patients, the authors observed a 2.4-point $(34.7 \%)$ improvement in VAS back pain, a 3.8-point $(53.3 \%)$ improvement in VAS leg pain, and an 11.6point $(23.1 \%)$ improvement in ODI at 2-year follow-up. Similarly, among patients with grade I degenerative spondylolisthesis, the authors observed a 2.9-point (34.5\%) improvement in VAS back pain, a 3.0-point (35.3\%) improvement in VAS leg pain, and a 21.2-point (57.5\%) improvement in ODI at 2year follow-up. Notably, compared to normal and overweight individuals, the majority of obese patients experienced significant clinical improvements despite a previously reported slower recovery rate and more pronounced baseline disability. ${ }^{37,38}$ Although similar outcomes are observed among these studies in whole, the authors did not report expected outcomes based on presenting symptoms.

The current study has several limitations. A primary limitation of this study is related to our stratification system, which is based on the VAS back pain and VAS leg pain scoring system. VAS has been observed to vary when compared across a single cohort due to the subjective attributes associated with pain, ${ }^{39-42}$ and because of varying patient pain tolerance thresholds. ${ }^{43,44}$ Second, the generalizability of this study is limited because all patients included in the analysis underwent MISTLIF by 1 surgeon at a single academic institution. Third, rather than a comparison of PROs to calculate MCID values for the specific patient population, the PRO measures of the current study were compared to MCID values previously reported in literature, limiting the clinical and functional significance of the results. In order to mitigate this limitation, the percentage of patients achieving MCID was based on 2 methods of calculation. This more accurately conveyed the percentage of clinical and functional improvements observed. However, a prospective study examining PRO measures following MIS-TLIF, with a calculated MCID for the unique patient population analyzed should be performed to more effectively assess the degree of improvement a patient can expect over the first postoperative year. Fourth, the data regarding the length of postoperative analgesic use during the follow-up period is not available in the patient registry used. As such, the possible effect of postoperative analgesia on pain scores is not captured in this study. Fifth, the patient sample analyzed was small. Despite similar outcomes among the population as a whole and in previously published literature, this study may be underpowered to assess the degree of symptom improvement patients can expect following MIS-TLIF. Given that there were no statistical differences between $\mathrm{pBP}$ and $\mathrm{pLP}$ groups for preoperative spinal diagnoses, stratification based on diagnoses was deemed necessary although future prospective 
studies investigating possible differences in outcomes for radicular and nonradicular pain between spinal diagnosis would be useful. Finally, our rate of fusion assessment is limited in that we used x-ray radiographs in many of our radiographic evaluations in place of CT. Using $\mathrm{x}$-ray radiographs could have underrepresented patients with nonunion as compared to assessing with only CT.

\section{Conclusion}

Effective patient counseling incorporates an analysis of a patient's postoperative expectations. In this context, it is important to establish expectations and discuss the degree of symptom improvement a patient may experience following their procedure. The results of the current study suggest that patients may experience significant improvements in their back pain, leg pain, and reported disability over the first postoperative year following MIS-TLIF regardless of presenting symptoms. Similarly, the majority of patients may experience clinically meaningful improvements in their symptoms and associated disability following surgery. Patients generally experience the greatest improvement in their pain symptoms during the first 6 postoperative weeks and can expect a $38.7 \%$ and $50.0 \%$ reduction in their VAS back and leg pain scores over the first postoperative year. These results may provide surgeons with valuable data to counsel patients on the likelihood and magnitude of symptom improvement following MIS-TLIF.

\section{REFERENCES}

1. Chang H, Baek D-H, Choi B-W. The relationship between increased intervertebral disc height and development of postoperative axial neck pain after anterior cervical fusion. $J$ Korean Neurosurg Soc. 2014;55(6):343-347.

2. Peolsson A. Investigation of clinically important benefit of anterior cervical decompression and fusion. Eur Spine J. 2007;16(4):507-514.

3. Hessler C, Boysen K, Regelsberger J, Vettorazzi E, Winkler D, Westphal M. Patient satisfaction after anterior cervical discectomy and fusion is primarily driven by relieving pain. Clin J Pain. 2012;28(5):398-403.

4. Zigler JE, Rogers RW, Ohnmeiss DD. Comparison of 1level versus 2-level anterior cervical discectomy and fusion: clinical and radiographic follow-up at 60 months. Spine. 2016;41(6):463-469.

5. Pearson A, Blood E, Lurie J, et al. Predominant leg pain is associated with better surgical outcomes in degenerative spondylolisthesis and spinal stenosis: results from the Spine
Patient Outcomes Research Trial (SPORT). Spine. 2011;36(3):219-229.

6. Kleinstück FS, Grob D, Lattig F, et al. The influence of preoperative back pain on the outcome of lumbar decompression surgery. Spine. 2009;34(11):1198-1203.

7. Auffinger BM, Lall RR, Dahdaleh NS, et al. measuring surgical outcomes in cervical spondylotic myelopathy patients undergoing anterior cervical discectomy and fusion: assessment of minimum clinically important difference. PLOS ONE. 2013;8(6):e67408. doi:10.1371/journal.pone.0067408

8. Mathews HH, Long BH. Minimally invasive techniques for the treatment of intervertebral disk herniation. J Am Acad Orthop Surg. 2002;10(2):80-85.

9. German JW, Adamo MA, Hoppenot RG, Blossom JH, Nagle HA. Perioperative results following lumbar discectomy: comparison of minimally invasive discectomy and standard microdiscectomy. Neurosurg Focus. 2008;25(2):E20.

10. Lee P, Liu JC, Fessler RG. Perioperative results following open and minimally invasive single-level lumbar discectomy. J Clin Neurosci. 2011;18(12):1667-1670.

11. Rasouli MR, Rahimi-Movaghar V, Shokraneh F, Moradi-Lakeh M, Chou R. Minimally invasive discectomy versus microdiscectomy/open discectomy for symptomatic lumbar disc herniation. Cochrane Database Syst Rev. 2014;(9):CD010328.

12. Khajavi K, Shen A, Hutchison A. Substantial clinical benefit of minimally invasive lateral interbody fusion for degenerative spondylolisthesis. Eur Spine J. 2015;24(suppl 3):314-321.

13. Khajavi K, Shen AY. Two-year radiographic and clinical outcomes of a minimally invasive, lateral, transpsoas approach for anterior lumbar interbody fusion in the treatment of adult degenerative scoliosis. Eur Spine J. 2014;23(6):1215-1223. doi:10.1007/s00586-014-3246-6

14. Fairbank JC, Pynsent PB. The Oswestry Disability Index. Spine. 2000;25(22):2940-2952; discussion 2952.

15. Ware J Jr, Kosinski M, Keller SD. A 12-item short-form health survey: construction of scales and preliminary tests of reliability and validity. Med Care. 1996;34(3):220-233.

16. Rao PJ, Loganathan A, Yeung V, Mobbs RJ. Outcomes of anterior lumbar interbody fusion surgery based on indication: a prospective study. Neurosurgery. 2015;76(1):7-23; discussion 23-24.

17. Vilagut G, Forero CG, Pinto-Meza A, et al. The mental component of the Short-Form 12 Health Survey (SF-12) as a measure of depressive disorders in the general population: results with three alternative scoring methods. Value Health. 2013;16(4):564-573. doi:10.1016/j.jval.2013.01.006

18. Carreon LY, Bratcher KR, Canan CE, Burke LO, Djurasovic M, Glassman SD. Differentiating minimum clinically important difference for primary and revision lumbar fusion surgeries. J Neurosurg Spine. 2013;18(1):102-106.

19. Parker SL, Adogwa O, Paul AR, et al. Utility of minimum clinically important difference in assessing pain, disability, and health state after transforaminal lumbar interbody fusion for degenerative lumbar spondylolisthesis. $J$ Neurosurg Spine. 2011;14(5):598-604. doi:10.3171/2010.12. spine 10472

20. Parker SL, Mendenhall SK, Shau D, et al. Determination of minimum clinically important difference in pain, 
disability, and quality of life after extension of fusion for adjacent-segment disease. J Neurosurg Spine. 2012;16(1):61-67.

21. Parker SL, Adogwa O, Mendenhall SK, et al. Determination of minimum clinically important difference (MCID) in pain, disability, and quality of life after revision fusion for symptomatic pseudoarthrosis. Spine $J$. 2012;12(12):1122-1128.

22. Parker SL, Mendenhall SK, Shau DN, et al. Minimum clinically important difference in pain, disability, and quality of life after neural decompression and fusion for same-level recurrent lumbar stenosis: understanding clinical versus statistical significance. J Neurosurg Spine. 2012;16(5):471-478.

23. Gum JL, Glassman SD, Carreon LY. Clinically important deterioration in patients undergoing lumbar spine surgery: a choice of evaluation methods using the Oswestry Disability Index, 36-Item Short Form Health Survey, and pain scales. J Neurosurg Spine. 2013;19(5):564-568. doi:10.3171/ 2013.8.spine12804

24. Adogwa O, Carr K, Thompson P, et al. A prospective, multi-institutional comparative effectiveness study of lumbar spine surgery in morbidly obese patients: does minimally invasive transforaminal lumbar interbody fusion result in superior outcomes? World Neurosurg. 2015;83(5):860-866. doi:10.1016/j.wneu.2014.12.034

25. Atlas SJ, Keller RB, Robson D, Deyo RA, Singer DE. Surgical and nonsurgical management of lumbar spinal stenosis: four-year outcomes from the maine lumbar spine study. Spine. 2000;25(5):556-562.

26. Atlas SJ, Deyo RA, Keller RB, et al. The Maine Lumbar Spine Study, Part III. 1-year outcomes of surgical and nonsurgical management of lumbar spinal stenosis. Spine. 1996;21(15):1787-1794; discussion 1794-1795.

27. Choi K-C, Kim J-S, Kang B-U, Lee CD, Lee S-H. Changes in back pain after percutaneous endoscopic lumbar discectomy and annuloplasty for lumbar disc herniation: a prospective study. Pain Med. 2011;12(11):1615-1621.

28. Gautschi OP, Corniola MV, Smoll NR, et al. Sex differences in subjective and objective measures of pain, functional impairment, and health-related quality of life in patients with lumbar degenerative disc disease. Pain. 2016;157(5):1065-1071.

29. Gautschi OP, Smoll NR, Corniola MV, et al. Sex differences in lumbar degenerative disc disease. Clin Neurol Neurosurg. 2016;145:52-57.

30. Häkkinen A, Kautiainen H, Järvenpää S, ArkelaKautiainen M, Ylinen J. Changes in the total Oswestry Index and its ten items in females and males pre- and post-surgery for lumbar disc herniation: a 1-year follow-up. Eur Spine J. 2007;16(3):347-352. doi:10.1007/s00586-006-0187-8

31. Kim H-J, Suh B-G, Lee D-B, et al. Gender difference of symptom severity in lumbar spinal stenosis: role of pain sensitivity. Pain Physician. 2013;16(6):E715-E723.

32. Konstantinou K, Dunn KM, Ogollah R, Vogel S, Hay EM, ATLAS Study Research Team. Characteristics of patients with low back and leg pain seeking treatment in primary care: baseline results from the ATLAS cohort study. BMC Musculoskelet Disord. 2015;16:332.

33. Tschugg A, Löscher WN, Hartmann S, Neururer S, Wildauer M, Thomé C. Gender influences radicular pain perception in patients with lumbar disc herniation. $J$ Womens Health. 2015;24(9):771-776.
34. Parker SL, Asher AL, Godil SS, Devin CJ, McGirt MJ. Patient-reported outcomes 3 months after spine surgery: is it an accurate predictor of 12-month outcome in real-world registry platforms? Neurosurg Focus. 2015;39(6):E17.

35. Gum JL, Glassman SD, Carreon LY. Clinically important deterioration in patients undergoing lumbar spine surgery: a choice of evaluation methods using the Oswestry Disability Index, 36-Item Short Form Health Survey, and pain scales: clinical article. J Neurosurg Spine. 2013;19(5):564-568.

36. Parker SL, Adogwa O, Bydon A, Cheng J, McGirt MJ. Cost-effectiveness of minimally invasive versus open transforaminal lumbar interbody fusion for degenerative spondylolisthesis associated low-back and leg pain over two years. World Neurosurg. 2012;78(1-2):178-184. doi:10.1016/j.wneu.2011.09. 013

37. Wertli MM, Held U, Campello M, Schecter Weiner S. Obesity is associated with more disability at presentation and after treatment in low back pain but not in neck pain: findings from the OIOC registry. BMC Musculoskelet Disord. 2016; $17: 140$.

38. Auffinger B, Lam S, Kraninger J, Shen J, Roitberg BZ. The impact of obesity on surgeon ratings and patient-reported outcome measures after degenerative cervical spine disease surgery. World Neurosurg. 2014;82(1-2):e345-e352.

39. Radovanovic I, Urquhart JC, Ganapathy V, et al. Influence of postoperative sagittal balance and spinopelvic parameters on the outcome of patients surgically treated for degenerative lumbar spondylolisthesis. $J$ Neurosurg Spine. 2017;26(4):448-453.

40. Kim MK, Lee S-H, Kim E-S, Eoh W, Chung S-S, Lee CS. The impact of sagittal balance on clinical results after posterior interbody fusion for patients with degenerative spondylolisthesis: a pilot study. BMC Musculoskelet Disord. 2011;12:69.

41. Alqroom R. The quest of sagittal balance parameters and clinical outcome after short segment spinal fusion. Acta Inform Med. 2018;26(1):57-61.

42. Massie LW, Zakaria HM, Schultz LR, Basheer A, Buraimoh MA, Chang V. Assessment of radiographic and clinical outcomes of an articulating expandable interbody cage in minimally invasive transforaminal lumbar interbody fusion for spondylolisthesis. Neurosurgical Focus. 2018;44(1):E8. doi: $10.3171 / 2017.10$.focus 17562

43. Wang H, Huang B, Zheng W, et al. Comparison of early and late percutaneous endoscopic lumbar discectomy for lumbar disc herniation. Acta Neurochir. 2013;155(10):19311936.

44. Sun X, Zeng R, Li G, et al. Comparison of effectiveness and change of sagittal spino-pelvic parameters between minimally invasive transforaminal and conventional open posterior lumbar interbody fusions in treatment of low-degree isthmic lumbar spondylolisthesis [in Chinese]. Zhongguo Xiu Fu Chong Jian Wai ke Za Zhi. Chin J Repar Reconstr Surg. 2015;29(12):1504-1509.

Disclosures and COI: No funds were received in support of this work. No benefits in any form have been or will be received from any commercial party related directly or indirectly to the subject of this manuscript. No FDA device/drug status to 
report. I will not discuss unlabeled/investigational uses of any commercial product or device. IRB approval was granted for this study (ORA 14051301).

Corresponding Author: Kern Singh, MD, Department of Orthopaedic Surgery, Rush University Medical Center, 1611 W. Harrison St, Suite 300,
Chicago, IL 60612. Phone: (312) 432-2373; Fax: (708) 409-5179; Email: kern.singh@rushortho.com.

Published 11 November 2020

This manuscript is generously published free of charge by ISASS, the International Society for the Advancement of Spine Surgery. Copyright (C) 2020 ISASS. To see more or order reprints or permissions, see http://ijssurgery.com. 